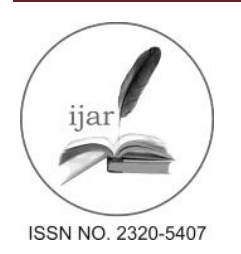

Journal homepage: http://www.journalijar.com
Journal DOI: $10.21474 /$ IJAR01

RESEARCH ARTICLE

\title{
PREPARING COMPETENT TEACHER FOR INCLUSIVE EDUCATION: UNDERSTANDING THE ROLE OF TECHNOLOGY.
}

\author{
Ratan Sarkar. \\ Research Scholar, Ramakrishna Mission Vivekananda University, Faculty of Disability Management and Special \\ Education, Coimbatore-641020, Tamil Nadu.
}

\section{Manuscript Info}

Manuscript History:

Received: 14 February 2016

Final Accepted: 28 March 2016

Published Online: April 2016

Key words:

Technology, Competent Teacher, Inclusive Education, Children with Special Needs.

\section{*Corresponding Author}

\section{Ratan sarkar.}

\begin{abstract}
The present era is called as the era of inclusion. As a result of social justice and human rights movement non-discriminatory education has now become one of the fundamental human rights of all including children with special needs (CWSN). To ensure this fundamental right inclusive education is the most viable option. Inclusive education is premised on a philosophy of educational reform which ensures that all children should learn together despite of their individual differences in any aspects and school must recognize and respond to the diverse needs of students, accommodating both different styles and rates of learning (Lipsky \& Gartner, 1999). An extensive research literature provides evidence that learning in and achievement of learner highly depends upon the competence of teachers (Gustafsson, 2003; OECD, 2005). Teacher competence is nothing but 'a complex combination of knowledge, skills, understanding, values, attitudes, visions of professionalism, theories of teaching and learning, quality cultures, sociocultural perspectives, and desire which lead to the effective implementation of teaching learning process and help in achieving its stipulated goals. Technology in education which refers to any hardware, software, tools, internet services, or equipments plays a vital role in the success of teaching learning process. Research supports that technology can play a vital role in enhancing the quality and competence of teacher and is used as remedial and compensatory alternative which circumvents deficits while capitalizing on an individual's strengths. However, the single most important factor in determining the success of technology in the education is a teacher who is comfortable with and knowledgeable about technology devices and its usefulness. Here lies the significance of technology education among teacher in order to enable them to cater the diverse needs of the CWSN in inclusive settings. The present paper attempts to bring forth the role of technology in enhancing the teachers' competency to meet the varied needs of CWSN in inclusive settings. This paper also highlights necessary steps to be taken for preparing competent teachers with sound knowledge of technology for successful implementation of inclusive education.
\end{abstract}

\section{Introduction:-}

Inclusive education has gained the acceptance as a process to reform education systems for ensuring quality education for all learners across the world. As a result of its success to address equal rights to education in different parts of the world, inclusive education is now considered as a viable strategy to create learning friendly environments for children/ persons with special needs, children from different ethnicity and language diversity, 
children who are from socially disadvantaged backgrounds and also gender issues. Inclusive education, which has emerged as a result of social justice movement, requires school to respond to the varying competencies of children (Sandil \& Singh, 2004). It is a human right approach and the philosophy for attaining equity, justice and quality education for all children. UNESCO (2005) defined it as: 'a process of addressing and responding to the diverse needs of all learners by increasing participation in learning and reducing exclusion within and from education.' The fundamental principle of inclusive school is that all children should learn together wherever possible regardless of any difficulties or differences they may have and Inclusive school must recognize and respond to the diverse needs of their students, accommodating both different styles and rates of learning and ensuring quality education to all through appropriate curricula, organizational arrangements, teaching strategies, resource use and partnership with their communities (Lipsky \& Gartner, 1999). The basic purpose of inclusive approach is to improve the quality of life through facilitating interactions between the children with and without special needs that would contribute to both bonding and building a complete inclusive society. For last few decades, inclusive education has become a focus of the both national and international educational Acts, policy and reform such as Sarva Shiksha Abhiyan (SSA, 2001); The Right of Children to Free and Compulsory Education (RTE) Act, (2009); The World Education Forum- EFA (Dakar, 2000); Salamanca Declaration (UNESCO, 1994); Millennium Development Goals (United Nations, 2008); and the UN Convention on the Rights of Persons with Disabilities (UNCRPD, 2006). Both developed (P. Forlin \& C. Forlin, 1998; Mittler, 2004) and developing (Ahsan \& Burnip, 2007; Alur, 2009; Singal, 2005) countries are engaged in meeting the challenges of inclusive education, ensuring schools are free from the negative effects of discrimination based on gender, disability, culture, ethnicity, religion or any other differences (UNESCO, 1994). India has also a strong commitment towards meeting 'Education for All' goals for inclusive education as demonstrated through a number of national policies such as the Sarva Shiksha Abhiyan (SSA, 2001); Rashtriya Madhyamik Shiksha Abhiyan (RMSA, 2009); Persons with Disabilities Act (PWD Act, 1995); The Right of Children to Free and Compulsory Education Act-2009 (RTE Act, 2009) and teacher's competency development initiatives that prioritize inclusive education as integral to mainstream.

\section{Teacher Competency:-}

Successful implementation of inclusive education programs depends on a numbers of variables. One such variable, and perhaps the most important one, is the teacher competency. An extensive research literature provides evidence that learning in and achievement of learner highly depends upon the competence of teachers (Gustafsson, 2003; OECD, 2005). Teacher competency is nothing but 'a complex combination of knowledge, skills, understanding, values, attitudes, belief, visions of professionalism, theories of teaching and learning, quality cultures, socio-cultural perspectives, and motivation which lead to the effective implementation of teaching learning process and help in achieving its stipulated goals. Teacher competency has a direct and positive effect on quality of education in inclusive settings. The National Council of Teacher Education (NCTE) has identified ten competencies for making teacher professionally competent. These are as follows.

1. Contextual Competency:- In this context teacher should have the abilities to understand various contexts, such as historical background, socio-economic condition, cultural, biological, physical, psychological, linguistic and religious condition of the children, family, and the community.

2. Conceptual Competency:- In conceptual competency teacher should have a clear thought and deep understanding of individual differences and needs, educational theories, and knowledge of various educational trends, teaching methods and techniques.

3. Content Competency:- In Content competency teacher should have full mastery knowledge on that content which they teach in the classroom.

4. Transactional Competencies:- In this context teacher should have full knowledge on how to organize teaching learning process more joyfully and activity centric.

5. Educational Activities Competency:- Here teacher should have clear thoughts on cognitive and non-cognitive areas. Because both areas are equally important to develop the quality of elementary education.

6. Competencies to Develop Teaching-Learning Material:- Teacher should have the ability to develop teaching aids technically for making teaching learning process more interesting.

7. Evaluation Competencies:- In this context teacher should be able to carry out continuous evaluation. An important objective of continuous evaluation is to diagnose the problems that children face in comprehending what is taught and in expressing what they know. So teacher needs the ability to undertake action research and promote multiples means of evaluation.

8. Management Competencies:- In this type competency teacher should have two-type management skill such as within the classroom and outside classroom management skill. 
9. Competencies Related to working with Parents:- The role of parents is equally important for the overall development of their children. To achieve the quality of education teacher should have the ability to work with parents.

10. Competencies Related to Working with Community:- No school can function in isolation to improve school situation, therefore in this context, the teacher should have the ability to work with the community and to use the resources of the community.

\section{Need of Competent Teacher for Successful Inclusive Education (IE); Supportive Reviews:-}

Savolainen (2009) notes that teacher's competence plays an essential role in quality education. Studies suggest (Sanders \& Horn, 1998) that the quality of the teacher contributes more to learner achievement than any other factor, including class size, class composition, or background. The need for competent teachers equipped to meet the needs of all learners becomes evident to provide not only equal opportunities for all, but also education for an inclusive society. Reynolds (2001) says that it is the knowledge, beliefs and values of the teacher that are brought to bear in creating an effective learning environment for pupils, making the teacher a critical influence in education for inclusion and the development of the inclusive school. Romi and Leyser (2006) reported that favorably disposed teachers toward the inclusion of students with disabilities in regular education classrooms employ more effective instructional strategies than those who hold negative attitudes. Researchers (Cook, 2001; Ross-Hill, 2009) have also found out that there is a positive correlation between supportive attitudes by teachers and enhanced performance by students with disabilities who were included in regular classrooms. Literature indicates that teachers' actions and performance in classrooms are greatly influenced by their knowledge of the learning characteristics of their students and these have profound impact on learning processes (Philpott, Furey, \& Penney, 2010; Pinar \& Sucuoglou, 2011). In a research conducted on regular primary and secondary school teachers in Delhi it was found that nearly $70 \%$ of the regular school teachers had neither received training in special education nor had any experience teaching students with disabilities (Das, A.K, Gichuri, M, \& Singh, A., 2013) whereas regular school teachers are increasingly required to be sensitive to the curricular needs, styles and rates of learning and levels of motivation of students with special needs. Teachers must have competencies in content, organization, evaluation and management as 'they are often expected to design, implement and evaluate the educational program based on the students' assessed needs and create active and appropriate learning situations through integrative, flexible and interdisciplinary instructional strategies (Kochhar \& West, 1996)'. They would also be required to participate in Individual Education Program (IEP) meetings and work in partnership with special education teachers, paraprofessionals, parents, and other service providers (Ashman \& Elkins, 2009). Therefore, it is evident that the teachers' competencies related to working with community and parents are also imperative to promote the inclusive education.

\section{Role of Technology in Enhancing Teachers' Competency:-}

Technology contributes to enhance the competencies of teachers in different ways. Such as-

1. Use of technologies helps teachers to update and develop their knowledge and skills actively and experientially, in a variety of learning environments, both individual and collaborative.

2. Technologies enable teachers to use a variety of learning strategies, encompassing direct instruction, deduction, discussion, drill and practice, deduction, induction, and sharing.

3. With the use of technologies teacher can create an authentic learning environment in order to engage students in concrete tasks within realistic scenarios.

4. Use of technologies help teacher to provide individualized instructions to the students with special needs according to their unique needs, abilities, interest and leaning pace.

5. Use of technologies help the teachers as well as learners for making a proper and judicious use of the multimedia and multi-sensory aid material, equipment and principles of teaching-learning, derived from psychology and technology of teaching.

6. Use of hardware and software may help the teachers in the task of managing their affairs related to the educational and professional responsibilities in the spheres as follows:

- Planning of teaching-learning.

- Organization of teaching-learning.

- Leading teaching-learning.

- Controlling teaching-learning. 
7. Use of technologies help both teachers and learners in the realization of their of their teaching-learning objectives by making the task of teaching-learning quite interesting, purposeful and productive through the provisions as follows:

- $\quad$ Suggesting suitable teaching-learning methods, devices and strategies based on the need and psychology of the learners.

- Suggesting suitable maxims and principles of teaching-learning based on the theory and practices of the technology of learning

- Putting various types of audio-visual aid material and equipment at the disposal of teachers and learners

- Providing a variety of instructional and self-learning material suiting the varying needs of teachinglearning situations and individuality of the teachers and learners.

8. Use of technologies help the teachers to make all possible efforts for providing adequate input and needed process organization to arrive at the best possible outcomes, i.e. realization of stipulated teaching, learning objectives in a most efficient and cost-effective way.

9. With the help of hardware and software technologies teacher can address various challenges in education system like - geographical location, distance, time, and quality assurance.

10. Technology makes teachers effective and motivated mentors, tutors, and guides of the students' learning process rather than simple presenters of knowledge and information.

11. Technology can develop teachers' skills in learning how to define learning objectives, plan and evaluate learning strategies, monitor progress, and adjust as needed.

12. Technologies can help teachers to promote cooperative and collaborative learning ensuring better parental and community involvement in teaching-learning process.

11. It helps teachers to be aware of and sensitive to the socio-economic, cultural, biological, physical, psychological, linguistic and religious condition of the children, family, and the community.

13. With the help of technologies teachers can more effectively work with more students with special needs in inclusive settings and it also helps teachers to develop greater level of independence, confidence, motivation, willingness to learn, and self advocacy among students with special needs.

Strategies to Prepare Competent Teachers with Sound Knowledge of Technology for I.E.:-

Although it is well established fact that technologies play a vital role to the development of teacher competencies, very little attention has been paid in this regard. However, the following strategies can be adopted to prepare competent teachers with sound knowledge of technology for the successful implementation of inclusive education (I.E.).

1. Encouraging Teachers to Acquire Necessary Skills:- For many teachers, having access to technologies is not viewed initially as a benefit. Teachers may consider technologies yet another demand on their time, a set of tools they did not ask for and do not know how to use. Some teachers feel they are already doing a good job in the classroom and wonder how technologies will contribute to improvements. Therefore, teachers must be sensitized about the needs of using technology and encouraged to use technology in the classrooms.

2. Framing Strong Policies and Ensuring It's Implementation:- Policies that either mandate or provide opportunities will cost money, but without the establishment of strong policy that mandates or provides professional-development opportunities (or, ideally, both), teachers are unlikely to acquire the skills they need to use the technologies available to them, thus negating the potential benefits of the investment that has been made in infrastructure.

3. Providing Sustained Support to Teachers for Using Technologies:- It is very important for teachers to acquire knowledge and skills in how to use technologies. But once teachers begin to acquire such skills and begin to use technologies, there is a need to provide means of continuing support to teacher to use technologies. That is, initial training of teachers is not likely to guarantee that the technology infrastructure will continue to be used. However, in-service training programmes can play a major role in this regard.

4. Evaluating Teachers' Use of Technologies:- The issue for education policy makers here concerns the extent to which a teacher uses technologies effectively, which can or should be an important criterion in evaluating a teacher's performance. This is a complicated issue for policy makers. However, establishing policy according to which teacher performance will be judged is of critical importance.

5. Offering a Mix of Opportunities, Incentives and Requirements:- Teacher engagement in competence development can be stimulated by offering a mix of opportunities, incentives and requirements. The opportunities for competence development should meet the following conditions: 
- Matching needs and demands at all levels - building a bridge between the needs of the teacher and those of the school (and education system);

- Accessibility, relevance and variety of opportunities on offer;

- Adequate provision of infrastructure, electricity, internet, technologies and other related support services.

6. Making Educational Technology an Integral Part of All Teacher Training Programmes:- Technology education should be considered an integral part of teacher training programmes at all level. Teacher pedagogical knowledge and beliefs should include knowledge of how technology can be used to solve their own problems. Therefore, it is needed to reform or create a complete syllabus of technology education which is capable enough to develop the competencies of teachers to promote full inclusion.

Others-

7. Government should take initiatives for restructuring the educational institutes in inclusive line.

8. Adequate funding to purchase, update and repair the technologies in schools.

9. Conducting workshops, seminar, and short term training programmes for professional development of the teachers in technology use.

10. Developing positive attitude towards the use of technology in schools among institutions heads.

11. Understanding the role of social media in building the community network.

\section{Conclusion:-}

To conclude, it can be stated that technology has the potential to enhance the quality and competence of teachers. It can enable the teachers to address the unique individual needs of all learners in inclusive classrooms. Technology is also known as the equalizer both inside the classrooms and outside the classrooms for diverse learners including children with special needs. It can circumvent deficits while capitalizing on an individual's strengths. However, the single most important factor in determining the successful implementation of technology to promote inclusive education is teacher with positive attitude and adequate skills required for technology use. Hence, it is crucial to understand the role of technology education among teachers in enhancing their quality and competence for inclusive education.

\section{References:-}

1. Ahsan, M.T., \& Burnip, L. (2007). Inclusive education in Bangladesh. Australian Journal of Special Education, $31(1), 61-71$.

2. Alur, M. (2009). Key elements of successful inclusive practice: Policy change on a macro sustainable level. In M. Alur, \& V. Timmons (Eds.), Inclusive education across cultures: Crossing boundaries, sharing ideas (pp. 107-120). New Delhi: SAGE.

3. Ashman, A., \& Elkins, J. (2009). Educating Students with Diverse Disabilities. French Forest (NSW): Prentice Hall.

4. Cook, B. G. (2001). A comparison of teachers' attitudes toward their included students with mild and severe disabilities. The Journal of Special Education, 34(4), 203-213.

5. Das, A. K., Gichuri, M., \& Singh, A. (2013). Implementing inclusive education in Delhi, India: Regular school teachers' preferences for professional development delivery modes. Professional Development in Education, 39(5), 698-711.

6. Forlin, P., \& Forlin, C. (1998). Constitutional and legislative framework for inclusive education in Australia. Australian Journal of Education, 42(2), 204-217.

7. Gustafsson, J. (2003). What do we know about the effects of school resources on educational results? Swedish Economic Policy Review, 10, 77-110

8. Kochhar, C. A., \& West, L. L. (1996). Handbook for successful inclusion. Gaithersburg, MD: Aspen.

9. Lipsky, \& Garner, A. (1999). Inclusive education: A Requirement of democratic society. In Garner (1999, Eds.). Inclusive education: Supporting inclusion in education system. London: Kogan Publication.

10. Mittler, P. (2004). Building bridges between special and mainstream services. Retrieved from http://www.eenet.org.uk/resources/docs/build_bridges.php, on 11.12.2015.

11. National Council of Educational Research and Training (NCERT). (2009). Comprehensive evaluation of centrally sponsor scheme on restructuring and reorganization of teacher. Education: A report of NCERT. New Delhi: NCERT.

12. OECD. (2005). Teachers matter. Attracting, developing and retaining effective teachers. Paris: OECD. Retrieved from: http://www. oecd.org/document/9/0,3343,en_2649_39263231_11969545_1_1_1_1,00.html, on 11.12.2015. 
13. Philpott, D. F., Furey, E., \& Penney, S.C. (2010). Promoting leadership in the ongoing professional development of teachers: Responding to globalization and inclusion. Exceptionality Education International, 20(2), 38-54.

14. Pinar, E. S., \& Sucuoglu, B. (2011). Turkish teachers' Expectancies in Inclusive Classrooms. Theory and Practice, 11(1), 395-402

15. Reynolds, M. (2001). Education for Inclusion, Teacher Education and the Teacher Training Agency Standards. Journal of In-Service Training, 27(3).

16. Romi, S., \& Leyser, Y. (2006). Exploring inclusion pre-service training needs: A study of variables associated with attitudes and sell-efficacy beliefs. European Journal of Special Needs Education, 21(1), 85-105

17. Ross-Hill, R. (2009). Teacher attitude towards inclusion practices and special needs students. Journal of research in Special Needs education, 9(3), 188-198.

18. Sanders, W. \& Horn, S. (1998). Research findings from the Tennessee value-added assessment system (TVAAS) database: Implications for educational evaluation and research. Journal of Personnel Evaluation in Education, 12(3), 247-256.

19. Sandil \& Singh. (2004). Practice in inclusive education. Journal of Childhood Disability Update, 1(3), 26.

20. Savolainen, H. (2009). Responding to diversity and striving for excellence: The case for Finland. In Acedo, C. (Eds.) Prospects Quarterly Review of Comparative Education, 39(3).

21. Singal, N. (2005). Mapping the field of inclusive education: A review of the Indian literature. International Journal of Inclusive Education, 9(4), 33- 350.

22. UNESCO. (1994).The Salamanca statement and framework for action on special need education. Salamanca: UNESCO.

23. UNESCO. (2005). Guidelines for inclusion: Ensuring access to education for all. Paris: UNESCO.

24. United Nations. (2008).The millennium development goals report. New York: UN.

25. https://en.wikipedia.org/wiki/Right_of_Children_to_Free_and_Compulsory_Education_Act.11.12.2015.

26. https://en.wikipedia.org/wiki/Sarva_Shiksha_Abhiyan.11.12.2015.

27. ttp://www.unesco.org/education/efa/wef_2000/.10.11.2015.

28. http://mhrd.gov.in/rmsa.11.12.2015. 